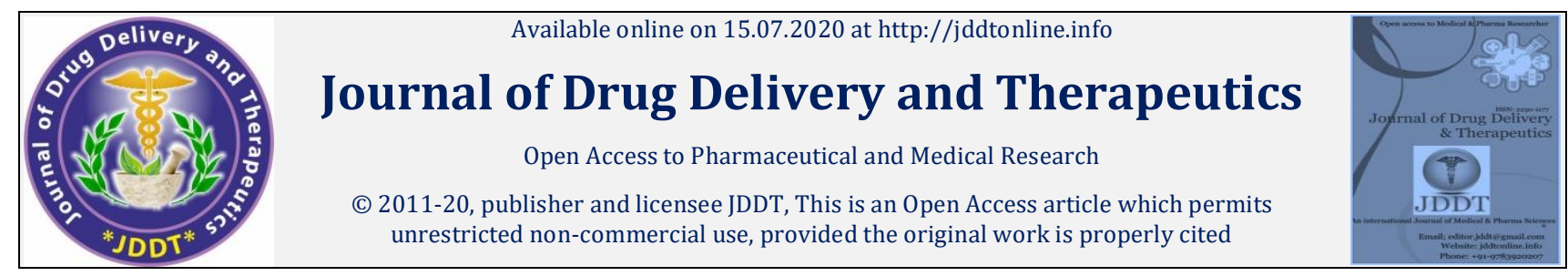

Open $\odot$ Access

Research Article

\title{
Method Development and Validation of Gemifloxacin in Tablet Dosage Form by RP-HPLC
}

\author{
Mithun Rudrapal1*, Nazim Hussain ${ }^{2}$ \\ ${ }^{1}$ Sandip Institute of Pharmaceutical Sciences, Sandip Foundation, Nashik, Maharashtra, India \\ 2 Kingston Imperial Institute of Technology and Sciences, Dehradun, Uttarakhand, India
}

\begin{abstract}
A simple, precise and accurate RP-HPLC method was developed and validated for the estimation of gemifloxacin in the tablet dosage form. The separation was achieved on a reversed-phase C-18 column ( 250 x $4.6 \mathrm{~mm}$ i.d., $5 \mu \mathrm{m})$ using a mobile phase consisting of acetonitrile/acetate buffer of $\mathrm{pH} 4.5(70: 30 \mathrm{v} / \mathrm{v})$ at a flow rate of $1.0 \mathrm{ml} / \mathrm{min}$ and a detection wavelength of $244 \mathrm{~nm}$. The separation was carried out on an isocratic mode at room temperature. The method was validated as per ICH guidelines for linearity, accuracy, precision, robustness, LOD, LOQ and specificity. The developed method showed good linearity over the concentration range of $50-150 \mu \mathrm{g} / \mathrm{ml}\left(r^{2}=0.995\right)$. The average percentage recovery was $99.77 \%$. The LOD and LOQ were $12.678 \mu \mathrm{g} / \mathrm{ml}$ and $14.261 \mu \mathrm{g} / \mathrm{ml}$, respectively. Based upon validation studies, the developed method can be successfully applied for the routine analysis of gemifloxacin in bulk drugs as well as pharmaceutical dosage forms.
\end{abstract}

Keywords: Gemifloxacin, Tablet dosage form, RP-HPLC, Validation, ICH guidelines

Article Info: Received 24 April 2020; Review Completed 19 June 2020; Accepted 28 June 2020; Available online 15 July 2020

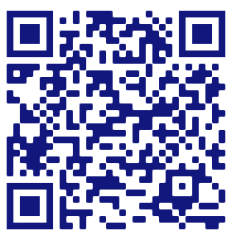

Cite this article as:

Rudrapal M, Hussain N, Method Development and Validation of Gemifloxacin in Tablet Dosage Form by RP-HPLC, Journal of Drug Delivery and Therapeutics. 2020; 10(4):97-101 http://dx.doi.org/10.22270/jddt.v10i4.4217

*Address for Correspondence:

Mithun Rudrapal, Sandip Institute of Pharmaceutical Sciences, Sandip Foundation, Nashik, Maharashtra, India

\section{INTRODUCTION}

Gemifloxacin is an oral broad-spectrum quinolone antibacterial agent used in the treatment of chronic bronchitis and mild-to-moderate pneumonia. Chemically, gemifloxacin is 7-[(4Z)-3-(aminomethyl)-4-(methoxyimino) pyrrolidin-1-yl]-1-cyclopropyl-6-fluoro-4-oxo-1,4-dihydro1,8-naphthyridine-3-carboxylic acid (Figure 1) 1,2. It is an important antibacterial compound fall under the class of fluoroquinolone antibiotics and is available as the mesylate salt in the sesquihydrate form. The bactericidal action of gemifloxacin results from inhibition of the enzymes topoisomerase II (DNA gyrase) and topoisomerase IV, which are required for bacterial DNA replication, transcription, repair, and recombination 3,4 . It occurs as white to off-white crystalline powder usually soluble in methanol, dimethyl sulfoxide, and water ${ }^{5}$. In this paper, a simple and specific RPHPLC method was developed and validated (as per ICH guidelines) for the estimation gemifloxacin in the tablet dosage form.<smiles>CO/N=C1\CN(c2nc3c(cc2F)c(=O)c(C(=O)O)cn3C2CC2)CC1CN</smiles>

Figure 1: Chemical structure of gemifloxacin

\section{MATERIALS AND METHODS}

\section{Chemicals}

Acetonitrile, methanol and water (Merck, Rankem) used in the study were of HPLC grade. All other chemicals were of analytical grade. The gemifloxacin bulk drug was obtained as gift sample from Chandra Laboratories, Hyderabad. The tablet dosage form of gemifloxain was procured from the local medical store. 


\section{Apparatus and Instruments}

UV-Visible spectrophotometer (Analytical Technologies Ltd.), HPLC (Waters), ultra sonicator (Citizen, Digital Ultrasonic Cleaner), pH meter (Elico) and electronic weighing balance (Shimadzu) were used for analytical studies.

\section{Chromatographic Parameters}

Chromatographic analysis was performed on a RP-HPLC equipped with a pump, manual sampler and a UV detector. The chromatographic column was a Develosil Rp AqueousAR-5 C18 column $(250 \mathrm{~mm} \times 4.6 \mathrm{~mm}$ i.d., $5 \mu \mathrm{m})$. The column temperature was maintained at $25{ }^{\circ} \mathrm{C}$. The mobile phase consisted of acetonitrile/acetate buffer ( $\mathrm{pH} 4.5) /(70: 30 \%$ $\mathrm{v} / \mathrm{v}$ ). The separation was achieved on an isocratic mode at ambient temperature. The flow rate was $1.0 \mathrm{ml} / \mathrm{min}$ and the injection volume was $20 \mu \mathrm{l}$. The run time was $5.0 \mathrm{~min}$. The wavelength of UV detection was set at $244 \mathrm{~nm}$.

\section{Preparation of Solutions ${ }^{6,7}$}

About $100 \mathrm{mg}$ of gemifloxacin weighed into a $100 \mathrm{ml}$ volumetric flask, added to this $25 \mathrm{ml}$ of mobile phase, sonicated for 20 minutes and the volume was made up to the mark with the mobile phase to obtain a concentration of $1000 \mu \mathrm{g} / \mathrm{ml}$. Further dilutions were made with the same solvent to prepare a series of standard solutions in the concentration range of $50-150 \mu \mathrm{g} / \mathrm{ml}$ of gemifloxacin.

Twenty tablets were accurately weighed and finely powdered. Powder equivalent to $100 \mathrm{mg}$ of gemifloxacin was accurately weighed, transferred into a $100 \mathrm{ml}$ volumetric flask and dissolved in mobile phase to obtain a sample stock solution of $1000 \mu \mathrm{g} / \mathrm{ml}$. The solution was sonicated for 20 minutes and filtered through Whatman filter paper. Using the stock solution, final sample solutions were prepared in the concentration range of $50-150 \mu \mathrm{g} / \mathrm{ml}$ using the same solvent.

\section{RESULTS AND DISCUSSION}

Preliminary studies involved several trial runs using $\mathrm{C}_{18}$ reversed-phase columns, various mobile phase compositions and different flow rates for the separation of gemifloxacin with optimum chromatographic parameters (resolution, symmetry, tailing factor etc.). A $\mathrm{C}_{18}$ column $(250 \mathrm{~mm} \times 4.6$ $\mathrm{mm}$ i.d., $5 \mu \mathrm{m}$.) stationary phase with a mobile phase consisting of acetonitrile/ acetate buffer $(\mathrm{pH} 4.5)(70: 30 \mathrm{v} / \mathrm{v})$ at a flow rate of $1.0 \mathrm{ml} / \mathrm{min}$ and a detection wavelength of $244 \mathrm{~nm}$ afforded the best separation with well-resolved and sharp peak. The summary of optimum chromatographic conditions is depicted in Table 1.

Table 1: Optimum chromatographic conditions

\begin{tabular}{|l|l|}
\hline Chromatographic parameter & Condition \\
\hline Mobile phase & Acetonitrile/ammonium acetate buffer $(\mathrm{pH} 4.5)(70: 30)$ \\
\hline Column & Develosil Rp Aqueous-AR-5 $(250 \times 4.6 \mathrm{~mm}, 5 \mu \mathrm{m})$ \\
\hline Flow rate & $1 \mathrm{ml} / \mathrm{min}$ \\
\hline Column temperature & Room temperature $\left(20-25^{\circ} \mathrm{C}\right)$ \\
\hline Sample temperature & Room temperature $\left(20-25^{\circ} \mathrm{C}\right)$ \\
\hline Wavelength & $244 \mathrm{~nm}$ \\
\hline Injection volume & $20 \mu \mathrm{l}$ \\
\hline Run time & $5 \mathrm{~min}$. \\
\hline Retention time & $3.084 \mathrm{~min}$. \\
\hline
\end{tabular}

After method development, validation of the developed method was performed in terms of the following parameters: linearity, accuracy, precision, robustness, limit of detection (LOD), limit of quantitation (LOQ) and specificity ${ }^{8-12}$.

\section{Linearity}

The linearity of the method was evaluated by analyzing six $(n=6)$ calibration standards of gemifloxacin for a concentration range of $50-150 \mu \mathrm{g} / \mathrm{ml}$ at $244 \mathrm{~nm}$. The plot of peak area versus concentration was found linear in the range of in the range of $50-150 \mu \mathrm{g} / \mathrm{ml}$ (Figure 2). The regression equation was obtained as follows: $y=19546 x+$ $49926\left(r^{2}=0.9953\right)$, where $y=$ peak area, $x=$ concentration of solution, $r=$ the square of determined correlation coefficient. From results it is clear that the developed method is linear over the specified range.

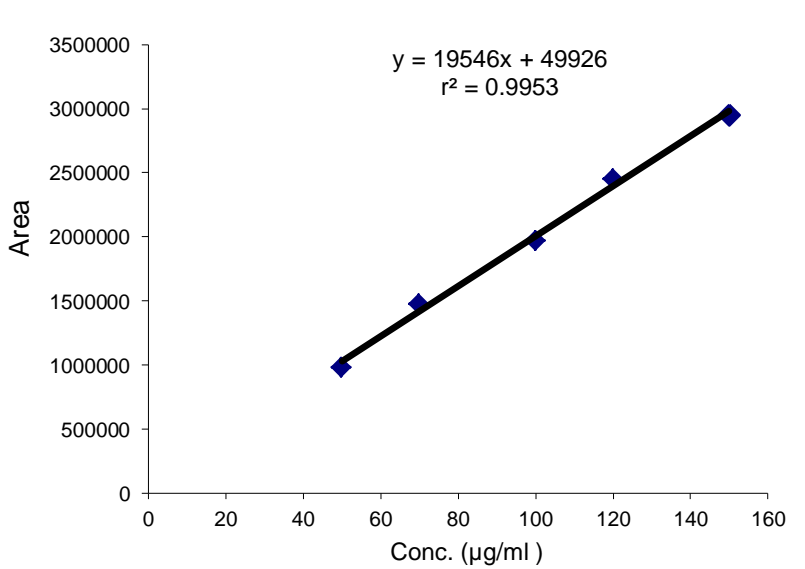

Figure 2: Calibration curve of gemifloxacin 


\section{Accuracy}

The accuracy of the method was determined by percentage recovery assay. A known amount of each standard powder (with the same proportion as in the drug formulation) was added to blank sample composed of all the excipients equivalent to the ratio of the tablet formulation, which was then mixed, extracted and subsequently diluted to obtain three different levels of concentration $(50,100$ and 150 $\mu \mathrm{g} / \mathrm{ml})$. The study was performed three times $(\mathrm{n}=3)$ at $50 \%$, $100 \%$ and $150 \%$ concentration. The method was found to be accurate with \% recovery of $99.77 \%$. The RSD values of peak areas were found to be less than $1 \%$ at each level.

\section{Precision}

The system precision and method precision were determined by analysing sample solution of gemifloxacin in six replications $(n=6)$. The $\%$ RSD values for system and method precision studies were found to be within the acceptance criteria of less than $2.0 \%$. Results indicate good precision of the developed method.

\section{Robustness}

The robustness of the methods was investigated by analyzing six replicates $(n=6)$ of sample solution by deliberate variations in the UV spectrometric measurements such as temperature and chromatographic conditions such as flow rate. Results of robustness studies indicate that the developed method is practically robust. The \% RSD values of the method determined under robustness conditions were less than $2.0 \%$.

\section{LOD and LOQ}

The LOD and LOQ for the developed RP-HPLC method were found to be $12.678 \mu \mathrm{g} / \mathrm{ml}$ and $14.261 \mu \mathrm{g} / \mathrm{ml}$, respectively. Results of LOD and LOQ imply that the developed method is sensitive for the precise determination of gemifloxacin in the marketed formulation.

\section{Specificity}

The standard and sample solutions $(100 \mu \mathrm{g} / \mathrm{ml})$ of gemifloxacin were injected and the chromatograms were recorded. No additional peaks due to impurities or other related substances were observed adjacent to the peak of interest in the chromatogram of gemifloxacin. The analyte peak for gemifloxacin was obtained with the retention time of $3.084 \mathrm{~min}$. Result of specificity studies demonstrates that the RP-HPLC method is highly specific. Chromatograms also indicate that the method is free from interferences due to excipients and/or related components (Figure 3).

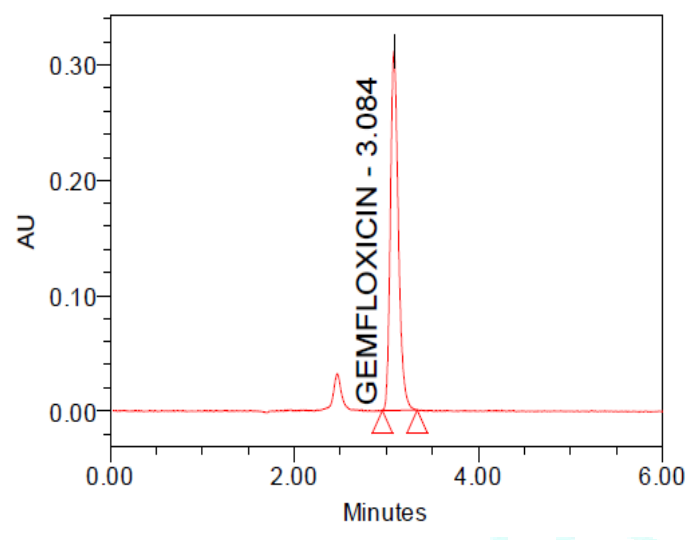

(a)

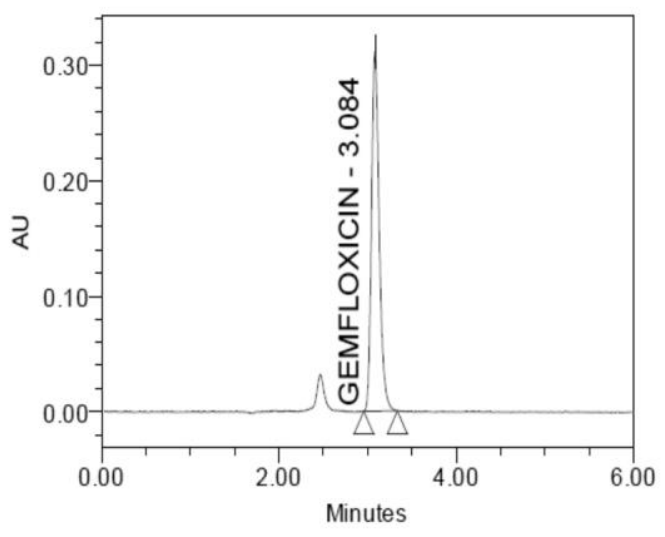

(b)

Figure 3: Chromatogram of standard (a) and sample (b)

\begin{abstract}
Assay
Weighed a quantity of powder equivalent to $100 \mathrm{mg}$ of gemifloxacin in $100 \mathrm{ml}$ volumetric flask and the volume was made up to the mark with mobile phase. From this stock solution, a sample solution of $100 \mu \mathrm{g} / \mathrm{ml}$ was prepared and used for the estimation of gemifloxacin. A chromatogram was recorded (Figure 4). The amount of gemifloxaxin in the tablet dosage form was calculated from the peak area of recorded chromatogram. The amount estimated was in good agreement with the label claimed. The assay of gemifloxacin (\% gemifloxacin) in the tablet dosage form was found to be $99.90 \%$. The percentage purity of gemifloxacin was found to be within the standard limit i.e., 98-102\%.
\end{abstract}

\section{System suitability}

System suitability was determined by injecting six replicate injections of the standard solution $(100 \mu \mathrm{g} / \mathrm{ml})$ of gemifloxacin ${ }^{13-15}$. Results of system suitability parameters depicted in Table 2 are within acceptable limit.

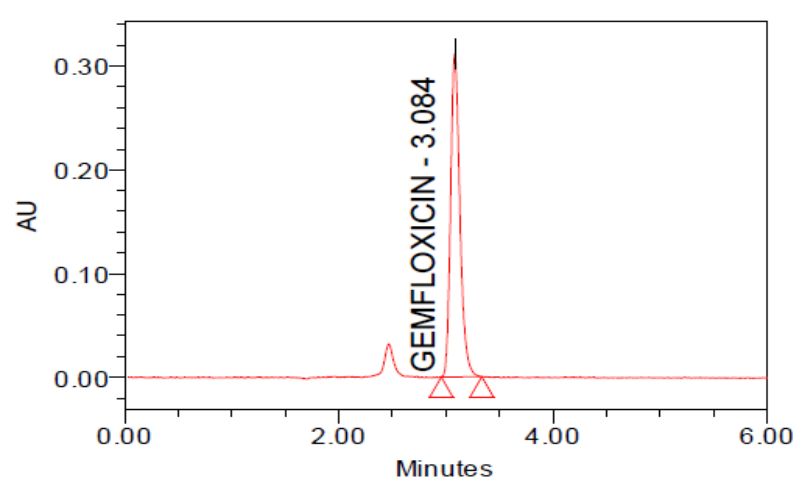

Figure 4: Assay chromatogram of gemifloxacin 
Table 2: Results of validation parameters

\begin{tabular}{|c|c|c|c|}
\hline Parameter & \multicolumn{3}{|l|}{ Result } \\
\hline \multicolumn{3}{|c|}{ Wave length of detection $\left(\lambda_{\max }, \mathrm{nm}\right)$} & 244 \\
\hline \multirow[t]{4}{*}{ Linearity } & \multicolumn{2}{|l|}{ Range $(\mu \mathrm{g} / \mathrm{ml})$} & $50-150$ \\
\hline & \multicolumn{2}{|l|}{ Slope } & 19546 \\
\hline & \multicolumn{2}{|l|}{ Intercept } & 49926 \\
\hline & \multicolumn{2}{|c|}{ Coefficient of correlation } & 0.9953 \\
\hline Accuracy & \multicolumn{2}{|l|}{ \% Recovery* } & $\%$ RSD $(<2.0)$ \\
\hline $50 \%$ & 99.13 & \multirow{3}{*}{$\begin{array}{l}\text { Average: } \\
99.77\end{array}$} & \multirow{3}{*}{$0.12-0.13$} \\
\hline $100 \%$ & 100.02 & & \\
\hline $150 \%$ & 100.18 & & \\
\hline Precision & \multicolumn{2}{|l|}{ Peak area** $^{* *}$} & $\%$ RSD $(<2.0)$ \\
\hline System precision & \multicolumn{2}{|l|}{1964334.83} & 0.13 \\
\hline Method precision & \multicolumn{2}{|l|}{1963997.00} & 0.12 \\
\hline Robustness $^{* *}$ & \multicolumn{2}{|l|}{ Peak area** } & $\% \operatorname{RSD}(<2.0)$ \\
\hline \multicolumn{3}{|l|}{ Wavelength (nm) } & \multirow{3}{*}{0.13} \\
\hline 242 & \multicolumn{2}{|l|}{2101531} & \\
\hline 246 & \multicolumn{2}{|l|}{2101435} & \\
\hline \multicolumn{3}{|l|}{ Flow rate $(\mathrm{ml} / \mathrm{min})$} & \multirow{3}{*}{0.12} \\
\hline 0.8 & \multicolumn{2}{|l|}{218891} & \\
\hline 1.2 & \multicolumn{2}{|l|}{2182155} & \\
\hline $\mathrm{LOD}(\mu \mathrm{g} / \mathrm{ml})$ & \multicolumn{2}{|l|}{12.678} & 0.12 \\
\hline LOQ $(\mu \mathrm{g} / \mathrm{ml})$ & \multicolumn{2}{|l|}{14.261} & 0.12 \\
\hline \multirow[t]{4}{*}{ System suitability } & \multicolumn{2}{|c|}{ Retention time (min.) } & 3.084 \\
\hline & \multicolumn{2}{|l|}{ Peak area } & 1962155 \\
\hline & \multicolumn{2}{|c|}{ Theoretical plates } & 6193 \\
\hline & \multicolumn{2}{|l|}{ Tailing factor } & 1.266 \\
\hline Assay* $^{*}$ & Amount (mg) & $\%$ Estimated & \\
\hline Label claim & 320.0 & 99.90 & \\
\hline Amount found & 319.8 & & \\
\hline
\end{tabular}

\section{CONCLUSION}

In this paper, a RP-HPLC method was developed and validated for the estimation of gemifloxacin in the marketed tablet dosage form. The developed method was successful for the estimation of gemifloxacin in the tablet formulation. The proposed method is claimed to be simple, accurate and precise. The developed method is also reported to be highly valid, specific and reliable. Based upon validation studies, the proposed method can be applied for the routine analysis of gemifloxacin in bulk drugs as well as pharmaceutical dosage forms.

\section{CONFLICT OF INTEREST}

The authors declare that there is no conflict of interest.

\section{REFERENCES}

1. Danta CC, Sahu S. Simple and Rapid Spectrophotometric Estimation of Gemifloxacin Mesylate in Bulk and Tablet Formulations. Int J Phar Tech Res 2011; 3(1):133-135.

2. Panda SS, Ravi Kumar BVV, Mohanta G, Patel PK. Reverse Phase Ultra-Fast Liquid Chromatographic Method for Determination of Gemifloxacin Mesylate in Tablet Dosage Form. J PharmaSciTech 2012; 2(1):20-25

3. Sagar BW, Anand MM, Sohan SC. Simultaneous spectrophotometric estimation of Gemifloxacin mesylate and Ambroxol hydrochloride in tablets. Anal Chem 2012; 11(5):188-194

4. Madhuri D, Chandrasekhar KB, Devanna N, Somasekhar G. Direct And Derivative Spectrophotometric Estimation of Gemifloxacin By Chelation With Palladium(II) Ion. Rasayan J Chem 2010; 3(1):159-165. 
5. Jyothirmayee D, Sai Babu GS, Devala Rao G. Spectrophotometric Determination of Gemifloxacin in Pharmaceutical Formulations. Asian J Chem 2010; 22(2):1634-1636.

6. Nagavalli D, Abirami G, Kumar SK Validated HPLC method for the simultaneous estimation of gemifloxacinmesylate and ambroxol hydrochloride in bulk and tablet dosage form. J Pharm Res 2011; 4(6):1701-1703.

7. Panchumarthy R, Garikapati D, Chapala D, et al. A validated RP-HPLC method for the determination of gemifloxacin in bulk and pharmaceutical dosage forms. J Chem Pharm Sci 2013; 6(1):46-54.

8. Naaz H, Srikanth P, Rudrapal M, Sarwa KK. Development and validation of analytical methods for the estimation of gallic acid in the herbal formulation of Amalaki by UV spectrophotometry and RP-HPLC. Asian J Chem 2020; in press.

9. Rudrapal M, Oduri MU, Samidala NR, Surya Kiran BVVS, Junejo JA, Singh KD, Chakraborty T, Debnath M. Development and Validation of RP-HPLC Method for Simultaneous Estimation of
Olmesartan and Hydrochlorothiazide in Tablet Dosage Form. Oriental J Chem 2015; 31(2):921-926.

10. Surya Kiran BVVS, Sridhar N, Raghavendra M, Rudrapal M. Development and validation of a RP-HPLC method for simultaneous estimation of minoxidil and aminexil in topical formulation. Asian J Chem 2016; 28(1):157-160.

11. Green JM, A Practical Guide to Analytical Method Validation. Anal Chem 1996; 689:305A-309A.

12. International Conference on Harmonization (ICH) of Technical Requirements for the Registration of Pharmaceuticals for Human Use, Validation of analytical procedures: Methodology, ICH-Q2B, Geneva, 1996.

13. Wegscheider W. Validation of analytical methods. In: Guenzler $\mathrm{H}$, editor. Accreditation and Quality Assurance in Analytical Chemistry. Berlin: Springer Verlag; 1996.

14. Michael E. Analytical Method Development. In: Swartz, Ira SK editors. Analytical Method Development and Validation. $1^{\text {st }}$ ed. New York: Marcel Dekker Inc; 2009.

15. Parida RK. Overview of Pharmaceutical Validation and Process Controls in Drug Development. Der Pharmacia Sinica 2010; 1(1):11-19. 